\title{
Current situation and awareness of pesticide abuse in agriculture in Vietnam
}

\author{
Danh Nguyen Tan \\ IT Department, FPT University, Vietnam
}

\begin{abstract}
Chemicals such as pesticides, antibiotics and hormones are used for plants and animals to boost production and ensure an adequate supply of food. However, when using these chemicals in excess of the maximum allowable limit in food can cause many unfortunate consequences for human health, from shortterm effects such as headaches and nausea to chronic effects such as cancer, damaging organs and causing many diseases. The harms of many pesticides and plant protection to human health and ecosystems in Vietnam are something that scientists, newspapers and many organizations have warned against for many years. Plant protection drugs are toxic to humans and livestock, adversely affect public health, pollute the environment, and kill both insects and beneficial microorganisms, thereby creating conditions for stronger disease development. If using the wrong technique, it will quickly create resistance to the insecticide. Plant protection drugs sometimes leave toxic residues on agricultural products, poisoning users, reducing the quality and competitiveness of agricultural products. The article uses the method of analyzing and comparing data and numbers to determine the impact of pesticides on human life. This paper also focuses on analyzing the use of homestead, the disadvantages, limitations, and negatives of the drugs to life and to raise awareness of drug users.
\end{abstract}

\section{Introduction}

There are hundreds of studies around the world that have investigated the serious harmful effects of agricultural chemicals [1]. The results showed that they are related to some types of cancer such as breast, prostate, brain, bone, thyroid, liver, lung, etc. Some researchers showed that the chemicals were methyl bromide or captan have the ability to cause prostate cancer.

In addition, women who want to have a baby or be pregnant consume pesticides that can increase the risk of brain cancer in the fetus [2]. Children who are exposed to certain amounts of pesticides containing phosphorus found in fruits and vegetables have a higher risk of developing hyperactivity disorder than children with less exposure. That also affects behavior and learning and cognitive ability in children [1].

The pesticides found in celery, peaches, apples, peppers, green vegetables, grapes and potatoes can affect the human nervous system. Signs of a poisoning include froth, stomach pain, vomiting, constipation or diarrhea.

Several studies have shown that pesticides alter the immune system in animals and they are more susceptible to disease due to poor resistance [3]. Pesticides enter the body to reduce the number of white blood cells and lymphocytes, which are used to prevent disease. They also make the body unable to resist viruses and bacteria. Most obese people have high concentrations of 2.5dichlorophenol (2.5-DCP) in their urine.
In addition, chlorpyrifos in the herbicides and pesticides reduce testosterone in men, and cause infertility and miscarriage in women [2]. This chemical is commonly found in fruits such as strawberries, apples and peaches. Pesticides are also harmful to pregnant women as chemicals cause various birth defects in the fetus.

\section{The use of plant protection drugs in the world}

In the world, plant protection drugs play an increasingly important role in preventing pests, protecting production, and ensuring food security. In the 1970s of the 20th century, plant protection drugs contributed to protect and increase yields by about $20-30 \%$ for major crops such as food, vegetables, and fruit.

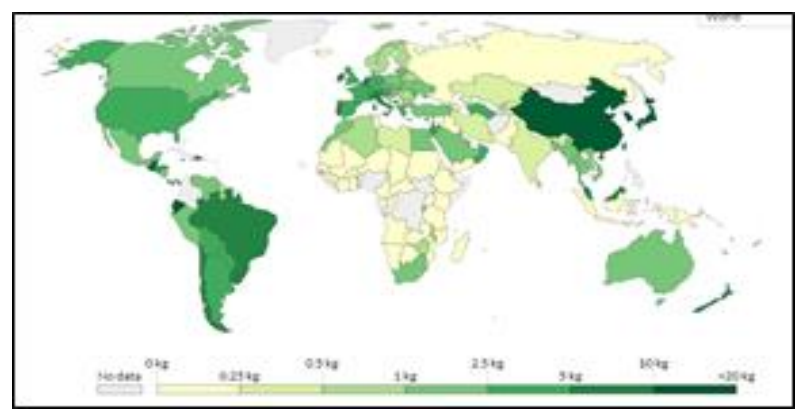

Figure 1. Pesticides use per hectare of cropland, 2017 (Source: UN Food and Agriculture Organization) 
However, in recent years, the abuse of plant protection drugs creates the risk of harming crops, the environment, public health, and reducing the economic efficiency of agricultural production [4]. The use of pesticides in the world for more than half a century has always increased, in 2000 it was 29.2 billion USD and in 2010 about 30 billion USD, in the last 10 years in 6 Asian countries where are growing rice, farmers use of plant protection drugs increases by $200-300 \%$ without increasing productivity (Figure 1).

Currently, the list of plant protection drugs in the world is thousands of types, usually 400-700 kinds in countries. (China 630, Thailand 600 types). The growth of plant protection drugs in recent years has been $2-3 \%$. China consumes $1.5-1.7$ million tons of pesticides annually.

As Asian countries grow a lot of rice, in the past 10 years $(2000$ - 2010), the use of pesticides increased by $200-300 \%$ but the yield was hardly increased, the number of pesticide sprays did not correlate or even inversely correlated with productivity [5]. The abuse of chemical plant protection chemicals also adversely affects the environment, ecosystems and public health, disrupting the sustainability of agricultural development [1]. The abuse of plant protection drugs increases drug resistance, degrades the parasite system, leaves toxic residues on agricultural products, soil and water, affects the quality of the environment, and poisones agricultural consumers. In the period 1996 - 2000, in developed countries, which are very strict about food hygiene and safety, there is still a situation of residues of plant protection chemicals on agricultural products such as the United States with $4.8 \%$, European community is $1.4 \%$, Australia is $0.9 \%$. South Korea and Taiwan are 0.8 $1.3 \%$. Due to the consequences and negative effects of the abuse of plant protection drugs, many countries around the world have been implementing a reform of the pesticide use strategy.

In fact, the safe and effective use of plant protection drugs is for business and technical purposes because there is not much mention about management issues, especially the goal of reducing the use of plant protection drugs. This new pesticide use strategy has been effective in many countries, especially Nordic countries where have succeeded in reducing pesticide use [6]. Within 20 years (1980-2000) Sweden reduced the amount of pesticides used by $60 \%$, Denmark and the Netherlands decreased by $50 \%$. The rate of increase in the consumption of plant protection drugs in the world in the past 10 years has gradually decreased, the structure of plant protection drugs has changed in the direction of increasing bio-products and environmentally friendly drugs. less toxic drugs, etc.

\section{Current situation of use of plant protection drugs in Vietnam}

\subsection{Affirming the important role of pesticides in agricultural production}

Plant protection drugs that were used in North Vietnam in the years 1955 have since proved to be the decisive means of quickly extinguishing large-scale pests and diseases. Therefore, we need to affirm the indispensable role of plant protection drugs in the agricultural production conditions of the country in recent years, now and in the coming time [3].

\subsection{Methodology}

This article uses data from the Vietnamese Department of Plant Protection and data from research papers. Through the analysis, the article emphasizes the importance of the awareness of using pesticides to the environment of a country with strong agricultural strengths like Vietnam.

\subsection{Results and discussion}

According to the Department of Plant Protection in the period 1981 - 1986, the number of drugs used was 6.5 to 9.0 thousand tons of commercial products, this number increased to 20-30 thousand tons in the period 1991 2000. and from $36-75.8$ thousand tons in the period 2001 - 2010. The amount of active ingredients per cultivated area ( $\mathrm{kg} / \mathrm{ha})$ also increased from $0.3 \mathrm{~kg}$ (1981 - 1986) to 1.24 - $2.54 \mathrm{~kg}$ (2001 - 2010). Plant protection drug import value also increased rapidly, in 2008 it was 472 million USD, in 2010 it was 537 million USD. The number of drugs registered for use also increased rapidly, before 2000 the number of active ingredients was 77, the trade name was 96, in 2000 it was 197 , and 722, by 2011 to 1202 and 3108 . So in the last 10 years. $(2000-2011)$ the number of plant protection drugs used increased 2.5 times, the number of imported drugs increased by about 3.5 times.

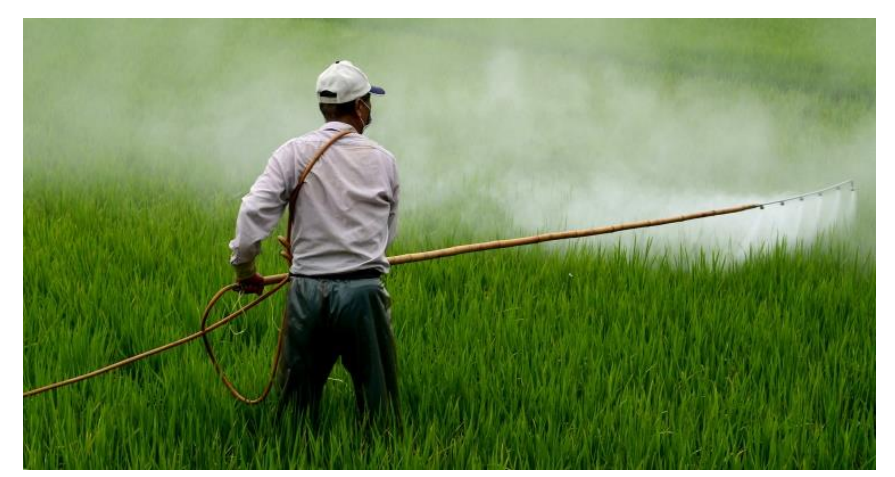

Figure 2. Theoveruse of pesticides in Vietnam

In 2010 , the amount of drugs used by Vietnam was equal to $40 \%$ of the average use of the four major countries using pesticides in the world (USA, France, Japan, and Brazil) while Vietnam's GDP was only $3.3 \%$ Of their average GDP (Figure 2). The number of active ingredients registered for use in Vietnam is currently approximately 1000 , while those of countries in the region range from 400 to 600 types, such as China: 630 types, Thailand, and Malasia 400 - 600 types. Pesticide use per capita in China is $1.2 \mathrm{~kg}$, and in Vietnam it is $0.95 \mathrm{~kg}$ (2010).

According to the Department of Plant Protection, by 2010, Vietnam has more than 200 plant protection 
companies, 93 factories, drug manufacturers and 28,750 stores and agents selling plant protection drugs [7]. While the pesticide inspection system is very weak, the mechanism of action is very difficult. One inspector in 2010 was in charge of 290 production and trading units of pesticides, 100,000 hectares of crops using pesticides, and 10,000 farming households using pesticides. Clearly this network is overloaded and difficult to control.

\subsection{The negative effects of plant protection drugs}

Pesticide residues on agricultural products are common and still high, especially on vegetables, fruits, tea, etc. Test results, in 2000 - 2002 by the Plant Protection Department show that in Hanoi, the number of samples has Residue excess is quite high, on vegetables, grapes, tea from $10 \%-26 \%$, in HCMC from $10-30 \%$. Ten years later, on vegetables, that figure is still $10.2 \%$ - plant protection drugs increase the resistance of pests and diseases, destroy natural enemy parasites, and can cause outbreaks of plant pests [8] According to Vietnam statistics, there are still over 706 tons of drugs to be destroyed and 19,600 tons of pesticide packaging waste that has not been collected and processed, and about 9,000 tons of new annual production is generated.

\subsection{Limitations in the use of plant protection drugs}

Firstly, the number of sprays of pesticides was too much, the sprays for tea in Thai Nguyen province ranged from 6.2 to 29.7 times / year, for rice in the Red River Delta from 1-5 times / crop, In the Mekong River Delta, 2-6 times / crop, over 6 times, there are $35.6 \%$ of households. The number of sprays for vegetables is from 7-10 times / crop in the Red River Delta, in Ho Chi Minh City 10-30 times.

In addition, when using drugs in the absence of technical knowledge, only $50 \%$ of grassroots agricultural technicians and extension workers correctly understand the technique of using pesticides, this rate among drug sellers. $33 \%$ in farmers $49.6 \%$.

Followed by the use of drugs exceeding the recommended dosage, arbitrarily using the mixture, only $22.1-48 \%$ of farmers used the correct concentration of medicine in rice, $0-26.7 \%$ in vegetables and 23.5$34.1 \%$ on tea, while many farmers increased dosage by 3 - 5 times. In the southern provinces, up to $38.6 \%$ used a higher dose than recommended, $29.7 \%$ arbitrarily mixed many drugs when spraying. In 2010, $19.59 \%$ of farmers nationwide violated drug use, of which the incorrect concentration was $73.2 \%$.

Next is the use of pesticides that do not comply with the quarantine period. This is a dangerous existence, having direct impacts on food safety and hygiene, but unfortunately very popular, especially in vegetable and tea areas up to $35-60 \%$ of farmers only practice now. The quarantine period is from 1-3 days, $25-43.3 \%$ perform quarantine for 4-6 days while the majority of drugs require isolation from 7-14 days or more.
Some people value benefits more than negative impacts on the environment and public health [9]. There is a very condemnable fact that a part of farmers deliberately use pesticides in contravention of legal and technical regulations for their own profit, taking legal and community benefits lightly. Especially in the areas of vegetables, fruits, tea, flowers, high-value agricultural products. Approximately 5.19\% of households use banned drugs, outside the list, $10.22 \%$ incorrectly in isolation, $51 \%$ do not Follow label recommendations.

Thus, it can be seen that the use of plant protection drugs in Vietnam in recent years is alarming, besides achievements and advantages, there are still many shortcomings, shortcomings and harms with objective and subjective causes. Including subjective reasons from the construction, promulgation, and implementation of management policies and techniques and subjective from the implementation side of the agricultural producer in the use of plant protection drugs.

\section{A number of solutions to improve the use of plant protection drugs}

We need to soon develop a strategy on the use of plant protection drugs in Vietnam in the next 10-15 years with orientations to reduce the use of plant protection drugs. We also need to improve the effectiveness of plant protection drugs in terms of technology, economic production, environmental protection, food safety and public health. To do this, we need to raise awareness, understanding and social responsibility of people who use plant protection drugs.

In addition, the use of plant protection drugs requires specific regulations on the formulation, issuance and use of a certain list [7]. Farmers need to limit the number of active ingredients in the list and limit the number of product names for one active ingredient. We also need to limit registration of new products as well as import of plant protection drugs; evaluation of technical efficiency and environmental, food safety, economic efficiency of active ingredients and additives [10]. Imported drugs must have certificates of origin and must be consistent with the registration dossiers; increase import tax on drugs that are not encouraged to use, and exempt from tax for drugs that encourage use, are environmentally friendly and less toxic. State agencies need to develop recommended lists to help farmers choose the right product [11].

It is quite important that the development of a roadmap to reduce risks and reduce the use of pesticides in Vietnam from now on in the direction of reducing annual drug use by $30-40 \%$, especially in rice, vegetables, tea, fruit, export agricultural areas; reduce the number of active ingredients in the list by $30-40 \%$; to raise the rate of bio-drugs, drugs of low toxicity, and environmentally friendly drugs to $40-60 \%$.

Finally, we need to develop a comprehensive program or project to expand the application of new technical advances to reduce, combat abuse and improve the effectiveness of pesticide use; strengthen inspection of plant protection drug use, application of new technical 
advances [6]. We also need to clearly define the rights and responsibilities of regulators and supervisors to check the proper use of plant protection drugs.

\section{Conclusion}

Plant protection drugs have positive effects on crop protection, increasing production efficiency. However, they are the cause of many serious environmental consequences. At the same time, it affects both the ecosystem and human health. Plant protection drugs are indispensable in agricultural production, but if used in excess, it will lead to very harmful consequences. Therefore, to harmonize the use of pesticides with the protection of public health and the environment is an important issue for modern agricultural production. In order to limit the use of plant protection drugs in production and restore a healthy ecological environment, the long-term solution is to continue to strengthen communication, awareness raising, understanding and change in practice. farmers' shops. To step up the program of agricultural extension and production of safe crops according to the process, we need to raise the strict control over the trading, trading, production and use of plant protection drugs. And one thing quite important, Besides, we need to find and apply beneficial pesticides in agricultural production.

\section{References}

1. Mahmood, I., Imadi, S. R., Shazadi, K., Gul, A., \& Hakeem, K. R. Effects of pesticides on environment. In Plant, soil and microbes (pp. 253-269). Springer, Cham. (2016).

2. Kabir, M. H., \& Rainis, R. Farmers' perception on the adverse effects of pesticides on environment: The Case of Bangladesh. International journal of sustainable agriculture, 42 (2012).

3. Carvalho, F. P. (2017). Pesticides, environment, and food safety. Food and Energy Security, 6(2), 48-60.

4. Cooper, J., \& Dobson, H. The benefits of pesticides to mankind and the environment. Crop Protection, 269 (2007).

5. Yuan-qing, B. U., Yuan, K. O. N. G., Yong, Z. H. I., Jin-yan, W. A. N. G., \& Zheng-jun, S. H. A. N. Pollution of Chemical Pesticides on Environment and Suggestion for Prevention and Control Countermeasures. Journal of Agricultural Science \& Technology (1008-0864), 16 2(2014).

6. Jayaraj, R., Megha, P., \& Sreedev, P. Organochlorine pesticides, their toxic effects on living organisms and their fate in the environment. Interdisciplinary toxicology, 9 3-4 (2016).

7. Maitah, M., Zidan, K., Hodrob, R., \& Malec, K. Farmers awareness concerning negative effects of pesticides on environment in Jordan. Modern Applied Science, 92 (2015).

8. Chaudhry, Q., Schröder, P., Werck-Reichhart, D., Grajek, W., \& Marecik, R. Prospects and limitations of phytoremediation for the removal of persistent pesticides in the environment. Environmental Science and Pollution Research, 91 (2002).

9. Sharma, D. R., Thapa, R. B., Manandhar, H. K., Shrestha, S. M., \& Pradhan, S. B. Use of pesticides in Nepal and impacts on human health and environment. Journal of Agriculture and environment, 13 (2012).

10. Toan, V. D., Thao, V. D., Walder, J., \& Schmutz, H. R. Contamination by selected organochlorine pesticides (OCPs) in surface soils in Hanoi, Vietnam. Bulletin of Environmental Contamination and Toxicology, 78 3-4 (2007).

11. Van Hoi, P., Mol, A., \& Oosterveer, P. State governance of pesticide use and trade in Vietnam. NJAS-Wageningen Journal of Life Sciences, 67(2013) 